\title{
Modeling assessment of investment risks in the regional socio-economic system
}

\author{
Evgeniy Butko ${ }^{1, *}$, Lyudmila Selivanova ${ }^{2}$ and Natalia Vasileva $^{2}$ \\ ${ }^{1}$ Moscow Polytechnic University, Bolshaya Semyonovskaya 38, Moscow, 107023, Russia \\ ${ }^{2}$ State institute of economics, finance, law, and technology, Roschinskaya 5, Gatchina, 188300, \\ Russia
}

\begin{abstract}
The paper defines methodological approaches to the assessment of investment risks in the social and economic system of the region. Based on the analysis of the conducted studies, a new model for assessing investment risk at the regional level in the conditions of certainty, uncertainty, and risk is proposed, which will allow assessing the probability of losing funds from investing financial resources. As a part of this model, a methodology for developing and making decisions under different conditions depending on the determinism or randomness based on the availability of information is presented. The calculations made allow choosing the optimal strategy of investment in the regional economy with different risk indicators, which are determined as the average annual rate of inflation.
\end{abstract}

\section{Introduction}

The investment processes in the regional socio-economic system, ensuring stable and sustainable development of the region, require the development of new methodological approaches to the analysis of investment risks and the adoption of reasonable investment decisions in the conditions of instability of the external and internal economic environment.

One of the most important components of the investment climate is investment risk, which is a characteristic of the probability of loss of investment and profits from it. The analysis of investment risk allows answering the question of the expediency of investing in a particular enterprise, industry, region, or country.

In this regard, the tasks of risk management and improvement of the process of making investment decisions in conditions of uncertainty and risk are very relevant.

In modern conditions, regional investment attractiveness is the determining factor for the intensification of investment activity. On the other hand, investment activity in the region is almost always associated with the following risks: economic, financial, social, political, legal, etc.

Investment risks are usually attributed to the group of financial risks. Thus, justifying the classification of investment risks by factors such as socio-political, economic, external balance factors, most researchers identify systemic (related to the economic situation in

\footnotetext{
*Corresponding author: nac-ek@mail.ru
} 
macroeconomics) and non-systemic or diversifying risks (links to the financial state of the investee) [1].

In the scientific research of both foreign and Russian researchers, different methods of risk assessment are used, which can be divided into subjective and objective [2].

Methods of expert assessments, which are used by rating agencies, are widely used among the subjective methods. The risk assessment is carried out here as a part of the investment attractiveness of the region [3].

The objective methods for assessing investment risks include statistical and analytical methods.

As for statistical methods in assessing investment risks, they are based on the calculation of such indicators as variance, standard deviation, coefficient of variation, risk factor. [4]

Analytical methods are based on probability accounting methods and provide a definition of the probability of loss based on mathematical models.

Among these are the methods of scenarios and the "decision tree" presented in various foreign studies [5].

The method ValueatRisk (VAR) was widely used. VAR is "the amount of losses on an investment portfolio for a fixed period of time, in case if an unfavorable event occurs". [6]

When implementing VAR, a number of methods are used:

- historical modeling, when the values of financial fluctuations of the investment portfolio already known from previous measurements are used;

- method of leading components;

- Monte Carlo method: calculations are performed on randomly generated values rather than on real data.

\section{Materials and Methods}

However, if we assess the investment risk for its individual types, this often leads to an increase in the uncertainty of the total risk. Assessment of the total investment risk from the implementation of regional investment activity at a possible level of losses is an alternative to assessing investment risk in the region.

In order to increase the efficiency of investment processes, it is important to give an accurate assessment of the investment climate in the region, which includes investment risks that show the likelihood of loss of funds from investing financial resources.

Within the framework of the improved model proposed by the authors, on the basis of the analysis of the functioning of the regional economic system, three groups of decisions based on the degree of risk are identified: conditions of certainty, uncertainty, and risk. The methodology for the development and decision-making of each group is dependent on determinism or randomness based on the availability of information [7].

The decisions of the first group are developed using methods of linear, nonlinear, dynamic mathematical programming that facilitates the solution of problems in the presence of sufficient information about the problem, the characteristics of the decisions made, and the features of their implementation.

The decisions of the second group are made under the influence of conditions of uncertainty. The choice of the best solution under these conditions is performed by solving the optimization problem. In the course of solving such problems, the effect of insufficient information, as well as various regional factors of social, economic, political, technical and other nature, is significantly manifested. In this case, methods of investigating operations, probability theory, game theory, etc. are used. Combination of different approaches helps determine the characteristics of the operation of the control subsystem with respect to reducing the level of uncertainty in the system. 

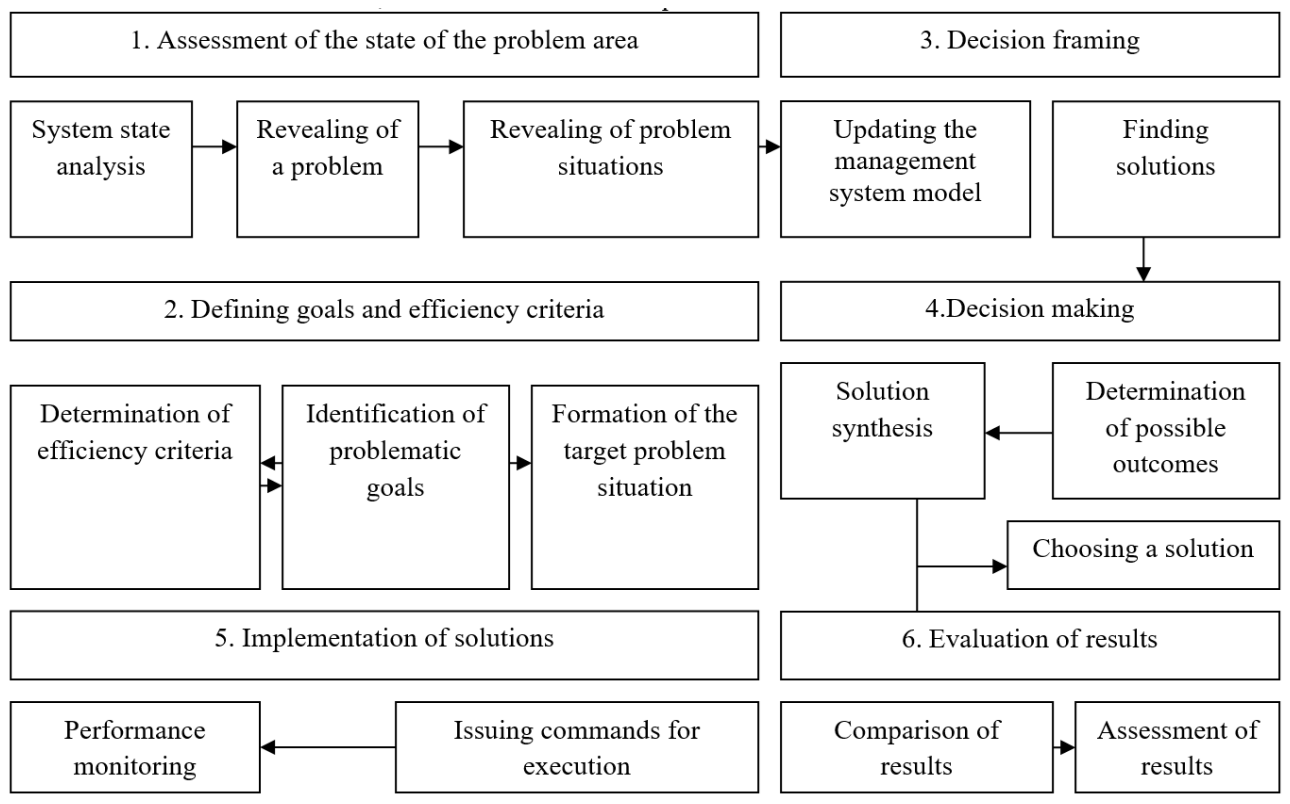

Fig.1. Logical scheme of interaction when making investment decisions in conditions of uncertainty.

The decisions of the third group are developed using nonparametric statistics methods, which allows reducing the influence of incomplete or inaccurate information with simultaneous consideration of random phenomena and processes. The Bayes-Laplace formulas contain indicators of risk assessment, which contributes to the formation of a model for the development of regional socio-economic processes. The result of the application of this tool is the formation of an algorithm for efficient management of the system in a risk environment [8].

The need to improve the mechanism for the development and making of management decisions is determined by the factor influence of a set of criteria for assessing the level of uncertainty in the regional economic situation and economic risk. The main characteristic of the development and making of management decisions in these conditions should be its effectiveness. In general, the effectiveness of the solution involves the ratio of the final result in the form of achieving the goals set to the amount of costs of all types. In this case, the parameters that characterize the decisions made during the development process can be divided into groups of known and unknown.

The following form of the formulation of the decision-making problem in the risk management system follows from the above: in accordance with the formulated integral criterion $\kappa$, choose the optimal solution $Y_{\text {opt }}$ from the set of admissible $Y \subset Y$ satisfying the system of constraints $G$ imposed on the available set of resources $R$ and the time interval $\mathrm{T}$.

The model of this solution is represented by the following conditions:

$$
\begin{gathered}
Y_{o p t}=o p t k(\min R) ; Y^{*} \subset Y, Y^{*} \subset S ; \\
Y_{o p t} \vee(G, K, T) ; k=f\left(k_{1}, k_{2} \ldots k_{m}\right),
\end{gathered}
$$

where $\kappa$ - an integral selection criterion for decision-making consisting of particular criteria characterizing various aspects under risk conditions;

$Y^{*}$ - an admissible solution satisfying the constraint system. 
When considering the model of the decision-making procedure under risk conditions, it can be seen that the sequence of decision-making under conditions of uncertainty and risk takes into account the influence of external factors that have probabilistic characteristics of the distribution of states $S \in S$.

On the assumption of availability of data on subjective probabilities of the future state of the regional economic environment, it is possible to use the information array contained in Table 1.

a) set of alternatives $A=\left\{a_{1}, a_{2}, \ldots a_{m}\right\}$ and set of components of the socioeconomic environment of the region $S=\left\{S_{1}, S_{2}, \ldots S_{n}\right\}$

b) subjective probabilities of the state of the environment (economic situation in the region)

$$
P\left(S_{1}\right), P\left(S_{2}\right), \ldots \sum_{i=1}^{n} P(S)=1
$$

c) functional utility $U_{i j}$ is defined for each combination of an alternative solution $a_{i}$ and state $S_{i}$, for example, GRP growth.

Table 1. Matrix of the initial states of the socio-economic environment of the region.

\begin{tabular}{|c|c|c|c|c|}
\hline \multirow{2}{*}{$\begin{array}{c}\text { Alternative } \\
\text { solutions }\end{array}$} & \multicolumn{4}{|c|}{ State of environment (economy) } \\
\cline { 2 - 5 } & $\mathrm{S}_{1}$ & $\mathrm{~S}_{2}$ & $\ldots$. & $\mathrm{S}_{\mathrm{n}}$ \\
\hline $\mathrm{a}_{1}$ & $\mathrm{U}_{11}$ & $\mathrm{U}_{12}$ & $\ldots$. & $\mathrm{U}_{1 \mathrm{n}}$ \\
\hline $\mathrm{a}_{2}$ & $\mathrm{U}_{21}$ & $\mathrm{U}_{22}$ & $\ldots$. & $\mathrm{U}_{2 \mathrm{n}}$ \\
\hline$\ldots$ & $\ldots$ & $\ldots$ & $\ldots$. & $\ldots$ \\
\hline $\mathrm{a}_{3}$ & $\mathrm{U}_{\mathrm{m} 1}$ & $\mathrm{U}_{\mathrm{m} 2}$ & $\ldots$. & $\mathrm{u}_{\mathrm{mn}}$ \\
\hline Probabilities & $\mathrm{P}_{\mathrm{s} 1}$ & $\mathrm{P}_{\mathrm{s} 2}$ & $\ldots$. & $\mathrm{P}_{\mathrm{sn}}$ \\
\hline
\end{tabular}

Management decisions under conditions of risk depend on the choice principle used, which is based on the use of probabilistic measures as an effective selection criterion. In the given conditions of the regional economic environment, it is possible to use the "BayesLaplace probabilistic measure", the "maximum utility function entropy principle", the "minimum utility variance principle", the "modal principle", the Wald's criterion, which take maximum account of the interrelationships of the basic elements under conditions of uncertainty and risk - alternatives, likelihood of achieving the expected result, uncertainty, possibility of deviation from a set goal.

1. Using the "Bayes-Laplace" principle, the probability-weighted sums of utilities are used as a criterion for assessing an alternative solution $\mathrm{a}_{\mathrm{i}}$, i.e.

$$
U_{i}=\sum_{i=1}^{n} P\left(S_{j}\right) U_{i j}
$$

Here we should consider the optimal solution for which the value of $U_{\mathrm{i}}$, which is the mathematical expectation of the utility function, is maximal, i.e.

$$
a^{o p t}=a^{*} \rightarrow \max _{i} U_{i}=\max _{i} \sum_{j=1}^{n} P\left(S_{j}\right) U_{i j},
$$

In the case where the probabilities are in a simple order, i.e.

$$
P\left(S_{1}\right) \geq P\left(S_{2}\right) \geq \ldots . P\left(S_{n}\right) \geq 0
$$


we will assume that the solution is preferable to $\left.a_{1}\left(a_{\kappa}\right\} a_{1}\right)$, if the following condition is satisfied:

$$
\begin{gathered}
U_{k}-U_{L}=\sum_{j=1}^{n} P\left(S_{j}\right)\left(U_{k j}-U_{L i}\right) \geq 0 \\
\text { If } P\left(S_{i} \geq 0\right), \sum_{j=1}^{n} P\left(S_{i}\right)=1 \text { or } U_{k}-U_{L}=\sum_{j=1}^{i}\left[\sum_{q=1}^{i}\left(U_{q k}-U_{q 1}\right)\left[P\left(S_{j}\right)-P\left(S_{j+1}\right)\right]\right],
\end{gathered}
$$

or taking into account that $P\left(S_{j}\right)-P\left(S_{i}\right) \geq 0$ we obtain:

$$
U_{k}-U_{L} \rightarrow \sum_{q=1}^{i}\left(U_{q k}-U_{q 1}\right) \geq 0
$$

Nearly for each solution $a_{i}$, it is advisable to match the amount of loss $W_{i j}=\left|U_{i j}-\max U_{i j}\right|$ that characterizes missed opportunities. Then

$$
a^{\text {opt }}=a^{*} \rightarrow \min _{i} \sum_{j=1}^{n} P\left(S_{i}\right) W_{i j}
$$

2. If the principle of "maximum entropy of the mathematical expectation of the utility function" is used, a universal criterion for determining the optimal investment strategy, expressed in the entropy of the mathematical expectation of the utility function, should be given:

$$
H_{i}=-\left[\sum_{j=1}^{n} P\left(S_{j}\right)\left(U_{i j}\right)\right] \cdot \ln \left[\left[\sum_{j=1}^{n} P\left(S_{j}\right) U_{i j}\right]\right]
$$

The optimal solution should be a solution containing the minimum entropy of the mathematical expectation of the utility function, i.e. $a^{\text {opt }}=a^{*} \rightarrow \min _{i} H_{i}$. If there is the following utility ratio: $U_{k}-U_{L} \rightarrow \sum_{q=1}^{n}\left(U_{q k}-U_{q 1}\right) \succ 0$ and each solution $a_{i}$ is associated with the amount of the losses $R_{i j}: R_{i j}=\left|U_{i j}-\max E_{i j}\right|$, which characterizes missed opportunities, not a utility function $\mathrm{U}_{\mathrm{ij}}$, then

$$
a^{o p t} \rightarrow \min \sum_{j=1}^{n} P\left(S_{i}\right) R_{i j}
$$

This indicator reflects the degree of uncertainty of the sought economic result and the degree of risk assumed by the controlling subsystem. In practice, the application of the entropy measure of the mathematical expectation of the utility function allows comparison and assessment of the efficiency of use in the practice of decision-making of various models and methods of risk management. 
3. Using the principle of the "minimum utility function variance" helps to determine the average utility value for each alternative solution

$$
U_{i}=\sum_{j=1}^{n} P\left(S_{j}\right) U_{i j} \quad(\mathrm{i}=1,2 \ldots . \mathrm{m}),
$$

And variance

$$
\sigma_{i}^{2}=\frac{1}{n-1} \sum_{j=1}^{n} P\left(S_{j}\right)\left(U_{i j}-U_{i}\right)^{2},
$$

The optimal solution is found from condition:

$$
a^{o p t} \Rightarrow\left\{\begin{array}{c}
\min \sigma_{i}^{2} \\
U_{i} \geq U^{n},(i=1,2 \ldots m)
\end{array}\right.
$$

where $U^{n}$ - the maximum value of the utility function.

In this case, the utility index is a function of the standard deviation in a series of sets of characteristics of the state of the external cluster environment. To find $\mathrm{a}^{\text {opt }}$, it is possible to use other variance indices, including the variance next to the largest value of the utility function or next to its most probable value. The standard deviation $\sigma$ can be represented as a measure of uncertainty showing the variance of the values of performance indicators relative to the most probable in the future. In this case, the coefficient of variation calculated as follows:

$$
v=\frac{\sigma}{\bar{X}}
$$

where $\bar{X}$ - the expected average value of the performance indicator. Here it is possible to use the following risk scale:

less than 0.1 - weak;

from 0,1 to 0,25 - moderate;

more than 0.25 - high.

4. In the case of applying the modal principle, the control subsystem assumes the most probable state of the environment $(\mathrm{j}=\mathrm{k})$

$$
P\left(S_{k}\right)=\max _{j} P\left(S_{j}\right),
$$

In this case, within the modal principle, the manager assumes that the environment is in the state $S_{k}=\max _{j} P\left(S_{j}\right)$ and the optimal solution $\left(a^{o p t}\right)$ in this case is found from condition $a^{o p t} \Rightarrow \max _{i} U_{i k},(i=1,2 \ldots, m)$.

In the case when the maximum of the probability $\mathrm{P}\left(\mathrm{S}_{\mathrm{i}}\right)$ is realized for $\mathrm{N}$ states of the environment, starting with some $S_{k}, S_{k+1}, \ldots, S_{k+N}$, then the following condition is necessary for the optimal solution: 


$$
a^{o p t} \Rightarrow \max _{j} \frac{1}{N} \sum_{j=k}^{k+N} U_{i j},(i=1,2 \ldots, m),
$$

To increase the efficiency of decision making within this principle, the calculation of the utility function of the most probable combinations of the environment is used.

5. Using the Wald's criterion allows treating nature as an aggressively minded and consciously acting enemy.

$$
a^{o p t} \Rightarrow \max _{i} \min _{j} U_{i j},
$$

In accordance with the Wald's criterion, the best result is chosen from all the most unfortunate results. This is a reinsurance position of extreme pessimism, calculated for the worst case. The choice of such a strategy is determined by the investor's attitude to risk.

To make this decision, it becomes necessary to refine the description of the characteristics of each alternative, as well as the indicators used as an optimal criterion for risky investment decisions. Under these risk conditions, the correctness of the choice of a particular model for finding an option for implementing a solution depends both on the very nature of the problem inherent with the solution being developed and on the nature of the alternative to this solution.

When implementing economic decisions and developing measures, it is necessary to consider the analysis of the advantages and disadvantages of the alternative effective and to consider in detail each chosen advantage. When implementing the maximum efficiency of the chosen decision, it is important that the result is more meaningful than the predefined version [9].

Proceeding from this set in a risk environment, taking into account the variants of the proposed models for choosing the optimal investment option, we propose an approach using the given efficiency coefficients.

1. Using each of the previously mentioned methods of development and making managerial decisions in conditions of uncertainty and risk, as well as alternatives chosen for the implementation, an efficiency criterion is calculated.

2. All used methods are weighted, for example, on a scale of 0 to 10 , and the significance is calculated as follows:

$$
\psi_{i}=\frac{V\left(\psi_{i}\right)}{\sum_{i=1}^{n} V(\psi)}
$$

where $V\left(\psi_{i}\right)$ - expertly assigned weight of the used method;

$\mathrm{n}$ - number of used decision-making methods;

3. The rationing and calculation of the reduced efficiency coefficients $E_{H P m n}$ are performed relative to the significance of the decision-making methods under conditions of uncertainty and risk:

$$
E_{(m n)}=\psi_{i} \frac{E_{m n}}{\sum_{i=1}^{n} E_{m n}},
$$




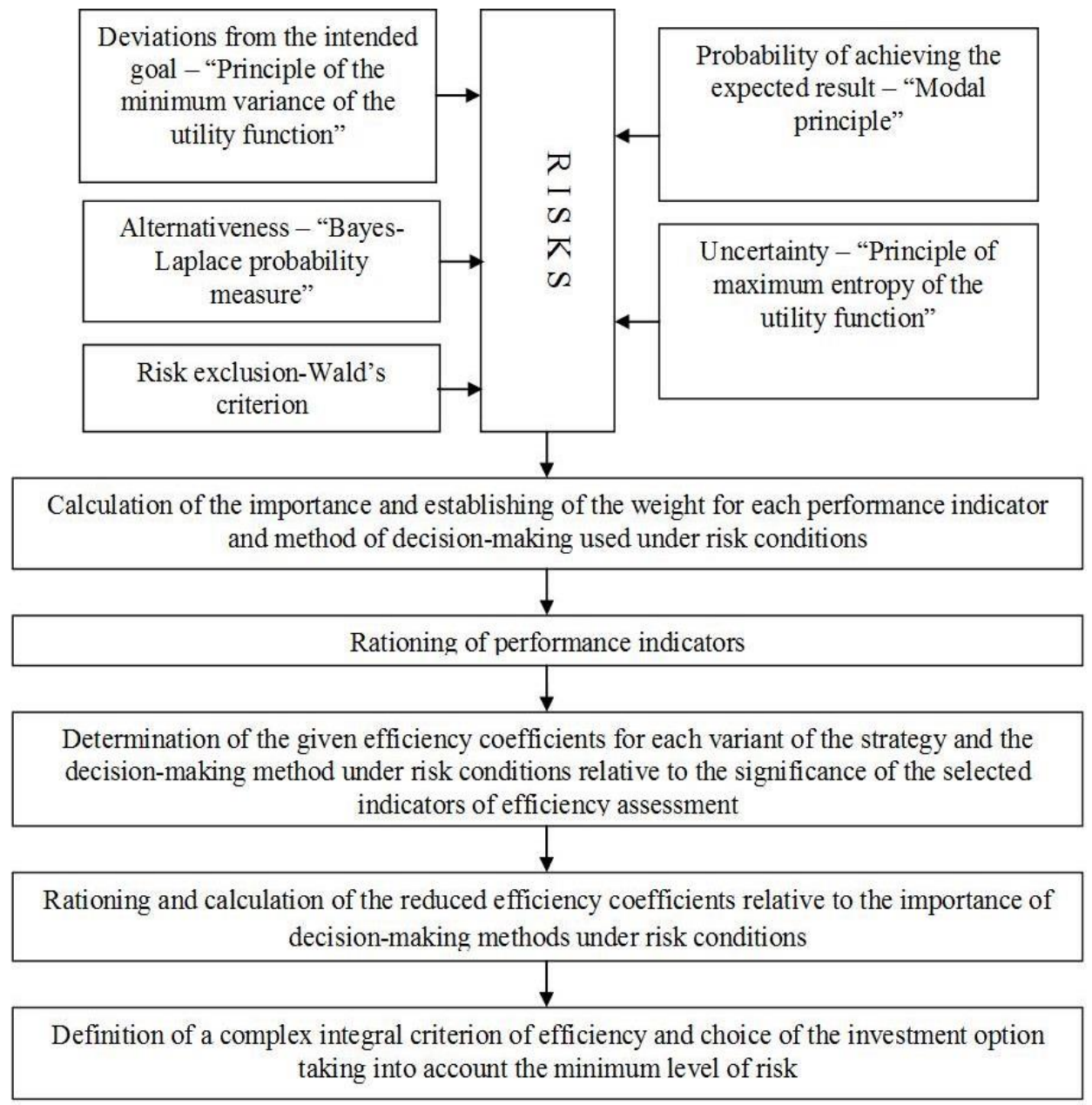

Fig. 2. Definition of a complex integral criterion of efficiency for investment decision making.

4. Definition of a complex integral criterion of efficiency:

$$
E_{(i n t)}=\sum_{i=1}^{n} E_{m n}
$$

where $\mathrm{E}_{(\text {int })}$ - complex integral criterion of efficiency

5. Choosing an optimum variant of strategy in view of integral criterion of efficiency.

\section{Results}

The implementation of this approach can be illustrated by the following example:

The regional authorities are considering three investment projects from which it is necessary to choose the project with the greatest budgetary efficiency for 10 years. As an indicator of budgetary efficiency (utility), we will take taxable profit. Financial indicators of the projects are given in Table 2. 
The risk indicator is the average annual inflation rate for 10 years of project implementation. Based on expert assessments, it is established that the average annual inflation during the implementation of projects will be $5 \%, 7 \%, 9 \%$, and $10 \%$ with a probability of $35 \%, 40 \%, 15 \%$, and $10 \%$, respectively.

Table 2. Financial indicators of projects.

\begin{tabular}{|c|c|c|c|}
\hline $\begin{array}{c}\text { Name of } \\
\text { project }\end{array}$ & $\begin{array}{c}\text { Investment size, } \\
\text { mln. RUB }\end{array}$ & $\begin{array}{c}\text { Internal rate of } \\
\text { return, } \%\end{array}$ & $\begin{array}{c}\text { Average annual profit before } \\
\text { taxation, mln. RUB }\end{array}$ \\
\hline Project 1 & 50 & 20 & 15,7 \\
\hline Project 2 & 70 & 15 & 18,3 \\
\hline Project 3 & 90 & 12 & 21,0 \\
\hline
\end{tabular}

The payment matrix for such a case is shown in Table 3.

Table 3. Taxable profit for 10 years discounted to the level of inflation.

\begin{tabular}{|c|c|c|c|c|}
\hline \multirow{2}{*}{$\begin{array}{c}\text { Alternative } \\
\text { solutions }\end{array}$} & \multicolumn{4}{|c|}{ State of environment (economy), average annual inflation } \\
\cline { 2 - 5 } & $5 \%$ & $7 \%$ & $9 \%$ & $10 \%$ \\
\hline Project 1 & 92,1 & 83,8 & 76,6 & 73,3 \\
\hline Project 2 & 107,5 & 97,8 & 89,4 & 85,6 \\
\hline Project 3 & 122,9 & 111,8 & 102,1 & 97,8 \\
\hline Probabilities & $35 \%$ & $40 \%$ & $15 \%$ & $10 \%$ \\
\hline
\end{tabular}

Let's consider five variants of decision making:

1. The maximum Wald's criterion;

\begin{tabular}{|c|c|c|c|c|c|}
\hline \multirow{2}{*}{$\begin{array}{c}\text { Alternative } \\
\text { solutions }\end{array}$} & \multicolumn{2}{|c|}{ State of environment (economy), average annual inflation } & \multirow{2}{*}{$\min _{\mathrm{ij}}$} \\
\cline { 2 - 5 } & $\mathbf{5 \%}$ & $\mathbf{7 \%}$ & $9 \%$ & $10 \%$ & \\
\hline Project 1 & 92,1 & 83,8 & 76,6 & 73,3 & 73,3 \\
\hline Project 2 & 107,5 & 97,8 & 89,4 & 85,6 & 85,6 \\
\hline Project 3 & 122,9 & 111,8 & 102,1 & 97,8 & 97,8 \\
\hline
\end{tabular}

Project 3 is chosen.

The Bayes-Laplace's criterion;

\begin{tabular}{|c|c|c|c|c|c|}
\hline \multirow{2}{*}{$\begin{array}{c}\text { Alternative } \\
\text { solutions }\end{array}$} & \multicolumn{3}{|c|}{ State of environment (economy), average annual inflation } & \multirow{2}{*}{$\mathrm{U}_{\mathrm{i}}$} \\
\cline { 2 - 5 } & $5 \%$ & $\mathbf{7 \%}$ & $9 \%$ & $10 \%$ & \\
\hline Project 1 & 32,2 & 33,5 & 11,5 & 7,3 & 84,6 \\
\hline Project 2 & 37,6 & 39,1 & 13,4 & 8,6 & 98,7 \\
\hline Project 3 & 43,0 & 44,7 & 15,3 & 9,8 & 112,8 \\
\hline
\end{tabular}

Project 3 is chosen.

2. Criterion for the maximum entropy of the mathematical expectation of the utility function;

\begin{tabular}{|c|c|c|c|c|c|c|}
\hline \multirow{2}{*}{$\begin{array}{c}\text { Alternative } \\
\text { solutions }\end{array}$} & \multicolumn{2}{|c|}{ State of environment (economy), average annual inflation } & \multirow{2}{*}{$\mathrm{U}_{\mathrm{i}}$} & \multirow{2}{*}{ Entropy } \\
\cline { 2 - 5 } & $5 \%$ & $7 \%$ & $9 \%$ & $10 \%$ & & \\
\hline Project 1 & 32,2 & 33,5 & 11,5 & 7,3 & 84,6 & $-375,4$ \\
\hline Project 2 & 37,6 & 39,1 & 13,4 & 8,6 & 98,7 & $-453,4$ \\
\hline Project 3 & 43,0 & 44,7 & 15,3 & 9,8 & 112,8 & $-533,2$ \\
\hline
\end{tabular}

Project 1 is chosen.

3. Criterion for the minimum variance of the utility function; 


\begin{tabular}{|c|c|c|c|c|c|}
\hline \multirow{2}{*}{$\begin{array}{c}\text { Alternative } \\
\text { solutions }\end{array}$} & \multicolumn{2}{|c|}{ State of environment (economy), average annual inflation } & Coefficient \\
\cline { 2 - 5 } & $5 \%$ & $7 \%$ & $9 \%$ & $10 \%$ & of variance \\
\hline Project 1 & 92,1 & 83,8 & 76,6 & 73,3 & 0,15 \\
\hline Project 2 & 107,5 & 97,8 & 89,4 & 85,6 & 0,14 \\
\hline Project 3 & 122,9 & 111,8 & 102,1 & 97,8 & 0,13 \\
\hline
\end{tabular}

Project 3 is chosen.

4. The modal criterion;

Since the most probable are the states of the environment with inflation of $5 \%$ and $7 \%$, we get

\begin{tabular}{|c|c|c|c|}
\hline \multirow{2}{*}{ Alternative solutions } & \multicolumn{2}{|l|}{$\begin{array}{l}\text { State of environment (economy), average } \\
\text { annual inflation }\end{array}$} & \multirow{2}{*}{$\begin{array}{l}\text { Average value of the } \\
\text { utility function }\end{array}$} \\
\cline { 2 - 4 } & $5 \%$ & $7 \%$ & 88,0 \\
\hline Project 1 & 92,1 & 83,8 & 102,7 \\
\hline Project 2 & 107,5 & 97,8 & 117,3 \\
\hline Project 3 & 122,9 & 111,8 & \\
\hline
\end{tabular}

Project 3 is chosen.

Next, we will calculate the reduced efficiency coefficients for each decision-making method and project, and then the integral efficiency coefficients for each project.

Let's assign the efficiency coefficient to 1 if the project is chosen by this method and 0 if the project is not chosen. The coefficients of efficiency, the weights assigned to the various decision-making methods, and the significance calculated on their basis are given in Table 4.

Table 4. Calculation of the significance of decision-making methods.

\begin{tabular}{|c|c|c|c|c|c|}
\hline Alternative & \multicolumn{5}{|c|}{ Method of decision making } \\
\cline { 2 - 6 } solutions & $\mathbf{1}$ & $\mathbf{2}$ & $\mathbf{3}$ & $\mathbf{4}$ & $\mathbf{5}$ \\
\hline Project 1 & 0 & 0 & 1 & 0 & 0 \\
\hline Project 2 & 0 & 0 & 0 & 0 & 0 \\
\hline Project 3 & 1 & 1 & 0 & 1 & 1 \\
\hline Weight & 9 & 6 & 7 & 7 & 8 \\
\hline Significance & 0,24 & 0,16 & 0,19 & 0,19 & 0,22 \\
\hline
\end{tabular}

Table 5 shows the results of calculating the reduced efficiency coefficients and integral efficiency coefficients.

Table 5. The reduced and integral coefficients of efficiency.

\begin{tabular}{|c|c|c|c|c|c|c|}
\hline \multirow{2}{*}{$\begin{array}{c}\text { Alternative } \\
\text { solutions }\end{array}$} & \multicolumn{5}{|c|}{ Method of decision making } & \multirow{2}{*}{$\begin{array}{c}\text { Integral efficiency } \\
\text { criterion }\end{array}$} \\
\hline & 1 & 2 & 3 & 4 & 5 & \\
\hline Project 1 & 0 & 0 & 0,19 & 0 & 0 & 0,19 \\
\hline Project 2 & 0 & 0 & 0 & 0 & 0 & 0,00 \\
\hline Project 3 & 0,24 & 0,16 & 0,00 & 0,19 & 0,22 & 0,81 \\
\hline
\end{tabular}

As follows from the data in Table 5, the proposed methodology recommends choosing project 3 with an efficiency level of $81 \%$.

\section{Discussions}

Of course, the above example is a simplified illustration of the possibilities of the proposed methodology. In reality, the utility function may depend on a large number of heterogeneous factors and should be calculated as the difference in the advantages and disadvantages of each alternative, expressed in comparable units. For example, the 
accounting of the environmental consequences of the implementation of each alternative can make serious adjustments to the values of the utility function and, accordingly, affect the final choice.

Moreover, in such an interpretation, the utility function becomes subjective and dependent on the party that makes the decision. In particular, the commercial results of the project play the main role for the investor, while the authorities should take into account not only economic indicators but also social, environmental and other consequences when taking decisions on the support of an investment project.

\section{Conclusion}

As a universal unit of measure for calculating the utility function, it is advisable to use monetary units. This means that when analyzing the consequences that do not have a direct and immediate financial effect, it is necessary to use dummy variables that have a monetary dimension and are correlated with the original variables. Thus, the proposed model allows assessing alternative investment options and choosing the best option in terms of uncertainty and risk.

\section{References}

1. N. Safronova, E. Nezhnikova, A. Kolhidov, MATEC Web of Conferences 106, 08024 (2017) doi. 10.1051/matecconf/201710608024

2. A. Jones, G. Fallon, R. Golov, European Business Review 12(4) doi:10.1108/09555340010336871

3. M. Rafiei, H. Adeli, Structural Design of Tall and Special Buildings (2016)

4. A. Aminmansour, K. Moon, Journal of Architectural Engineering 16(2), 47-53 (2010)

5. P. Love, D. Edwards, Z. Irani, IEEE Transactions on Engineering Management 59(4), 6032087, 560-571 (2012)

6. Y.V. Larionova, S.A. Pavlova, Life Science Journal 12, 650 (2014)

7. Y. Panibratov, A. Larionov, Applied Mechanics and Materials 8, 725-726 (2015)

8. I.V. Ilin, A.I. Levina, O.Yu. Iliashenko, MATEC Web of Conf. 86, 05028 (2016) doi: $10.1051 /$ matecconf/20168605028

9. O. Kalinina, O. Valebnikova, Advances in Intelligent Systems and Computing 692, 1315-1322 (2018) doi: 10.1007/978-3-319-70987-1_139 